\title{
Uniqueness of the self-concept across the life span
}

\author{
JOHN H. MUELLER and MICHAEL J. ROSS \\ University of Missouri, Columbia, Missouri
}

\begin{abstract}
College students and elderly subjects made self-descriptiveness and other-descriptiveness ratings for the same set of 120 trait adjectives representing three levels of likability. Elderly subjects attributed a greater number of likable traits uniquely to their best friend than to themselves alone, whereas young adults judged themselves more favorably than the other person. The elderly were generally slower at making the descriptiveness decisions, but particularly for uniquely descriptive items, as though trait distinctiveness information was still obtained on a comparative rather than a prestored basis even after many years of developing the self-concept. Scores on a self-consciousness questionnaire revealed that elderly subjects were lower on both public and private self-consciousness, but not on social anxiety.
\end{abstract}

Many recent studies (e.g., Rogers, Kuiper, \& Kirker, 1977) with young adults have generated several reliable effects when information is processed in terms of its "self-descriptiveness." For example, trait adjectives (e.g., honest, kind, etc.) are generally remembered better when the study phase involves a decision such as "Does (X) describe you" than when it involves a decision such as "Does $(\mathrm{X})$ mean the same as $(\mathrm{Y})$." Given the memorial benefits of self-comparisons, and the alleged memory deficit associated with aging (Kausler, 1982), the question of to what extent age-related changes in the self-concept may be a factor in the memory deficit can be raised. Although the self-concept is probably formed at an early age, individuation likely is an ongoing activity over the life span. Furthermore, considerable attention has focused on how the elderly perceive changes in their personalities (e.g., McCrae \& Costa, 1982; Ryff, 1982). Any changes that occur in the selfschema as a person grows older could certainly affect the way in which new experiences are integrated into that entity, and thus how well they are remembered. There are several ways that age-related self-concept changes might be involved in information processing.

First, it could be that self-referencing of experiences becomes less automatic as we grow older. It has been argued that self-referencing of new material occurs spontaneously in young adults (Rogers et al., 1977). Given the characterization of youth as a period of "identity seeking," this spontaneity seems appropriate, but as the self-concept eventually becomes more established, spontaneous self-comparisons may become less frequent. Since elderly subjects are believed to be less spontaneous in using other beneficial strategies

Helpful comments were provided on an earlier draft by Donald Kausler and Joel Freund. Requests for reprints should be sent to J. Mueller, Psychology Department, 210 McAlester Hall, University of Missouri, Columbia, Missouri 65211. (e.g., imagery), they may also fail to benefit from spontaneous self-referencing of experiences.

Second, it has been observed that young adults who are higher in self-awareness benefit more from selfreference decisions than do those who are lower in selfconsciousness (Mueller, 1982; Turner, 1980). Perhaps elderly subjects are less inclined to be the introspective, reflective, self-aware persons who benefit most from self-comparisons.

A third possibility is that elderly subjects may possess a self-concept that is less stable or that is defined differently in terms of content. Recent research has shown that systematic distortions of the self-concept may restrict the benefits to be derived from self-comparisons to only certain material consistent with the distortion or may possibly eliminate such benefits altogether. For example, Davis and Unruh (1981) and Derry and Kuiper (1981) have examined self-referencing in depressed subjects and have found that depressives either show no benefits from self-comparisons, allegedly due to an unstable self-concept, or show processing benefits only for material consistent with a depressed self-image, presumably indicating a stable self-concept organized around a nonnormal focus. In terms of a content limitation, it might be that elderly subjects would benefit only from material related specifically to the aging component of the self-concept (e.g., retirement, illness, loneliness, isolation, etc.).

Finally, access to personally relevant information is often faster than access to other information (Keenan \& Baillet, 1980). Conceivably, elderly subjects would not benefit from self-comparisons as they should, because of the general slowing that occurs with aging (Kausler, 1982; Salthouse, 1982). In this case, the elderly may be as spontaneous, as self-aware, and as possessed of a stable self-image as young adults, but may require more time to access information in the selfschema or to assimilate an experience to the self-concept. 
In sum, there are at least four ways in which an agerelated change in self-image might affect information processing: (1) spontaneity or automaticity of selfreferencing, (2) degree of self-awareness, (3) altered content or stability of the self-image, and (4) speed of access to personally relevant information.

The specific aspect of self-reference examined here was trait distinctiveness, or the extent to which a trait adjective is descriptive. At one extreme, some traits may be considered to be unique in that these are features we consider to be more descriptive of ourselves than of other people. Other traits, although also selfdescriptive, are likewise descriptive of others and thus concern shared features. Intuition might suggest that we are well aware of our unique features on the basis of past interactions and reflections. In other words, we have prestored trait-distinctiveness information, possibly in terms of simply having traits hierarchically arranged in memory, with unique traits being at the top of the hierarchy. If so, it would be expected that uniquely descriptive traits can be accessed more rapidly than mutually descriptive or shared traits in self-reference decisions.

However, in a study designed to measure speed of access to the self-concept in young adults, Mueller, Ross, and Heesacker (1984) found that self-descriptiveness decisions were slower for unique traits than for shared traits. This result is more consistent with the notion of some comparative process, instead of prestored knowledge of trait distinctiveness. In other words, the distinctiveness of a trait may vary from one time to the next, and may also depend upon the context in which the self-descriptiveness decision is made. For example, being an American in Paris is more salient than in Peoria, and being elderly may be more salient on a college campus than on a golf course in St. Petersburg.

In terms of aging, this paradigm is of interest because it allows the examination of whether distinctive traits become more. accessible in self-comparisons as a person has spent more time articulating the selfconcept over the years. That is, is there a point at which one does not have to ponder descriptiveness, such that we go from a comparative or computed model of trait distinctiveness when young to a prestored version as we grow older, or does this basic comparative process continue at all ages? Furthermore, regardless of speed of access, do we perceive more or fewer traits as being uniquely descriptive, in absolute terms, as we grow older? Finally, regardless of the speed of access or the change in the number of unique descriptors, does memory change over the life span for unique versus shared traits?

\section{METHOD}

\section{Subjects}

The young adults were 10 college students enrolled in introductory psychology who participated in return for extra credit in their course. Ten elderly subjects were recruited from the community (Columbia, Missouri) and were paid $\$ 5.00$ for
Table 1

Subject Characteristics by Age (Standard Deviations in Parentheses)

\begin{tabular}{lcccc}
\hline & \multicolumn{2}{c}{ Elderly } & \multicolumn{2}{c}{ Young } \\
\hline Age in Years & 71.5 & $(6.33)$ & 21.6 & $(3.54)$ \\
Years Education & 15.3 & $(3.27)$ & 14.3 & $(1.41)$ \\
WAIS (Part 2)* & 17.5 & $(1.51)$ & 14.4 & $(2.13)$ \\
State Anxiety & 52.3 & $(6.67)$ & 52.7 & $(4.55)$ \\
Public Self-Consciousness* & 19.6 & $(7.47)$ & 26.4 & $(5.36)$ \\
Private Self-Consciousness* & 22.0 & $(4.06)$ & 36.7 & $(4.62)$ \\
Social Anxiety & 18.4 & $(5.23)$ & 17.3 & $(4.42)$ \\
\hline
\end{tabular}

*Age difference significant at $p<.05$.

their participation. All were living at home and were in good general health at the time they participated. There were five men and five women in each group, but because sex differences in the results were minimal, this factor will not be considered further. Further details about the characteristics of each sample are summarized in Table 1.

\section{Materials}

The items rated were 120 trait adjectives selected from the Anderson (1968) norms. Forty words had likability ratings above 4.50 (e.g., capable, forgiving), and 40 had likability ratings below 1.64 (e.g., hostile, rude). The remaining 40 items were selected from the middle of the likability range, with values above 2.02 and below 3.51 (e.g., cautious, methodical). The rated meaningfulness of the three subsets was comparable $($ means $=3.69,3.53$, and 3.66).

\section{Procedure}

In the first phase of the experiment, each subject rated all 120 words for self- (or other-) descriptiveness. Each subject then rated all 120 words a second time for other- (or self-) descriptiveness. The judgments of other-descriptiveness used "your best friend" as the target. The order of the two targets was varied as first and second tasks across subjects. The words were presented in random order on a video display controlled by a PDP-11/34 computer. The subjects responded to each word by pressing one of the number keys (1-8) at the top of the keyboard ( 1 was nondescriptive of the target, and 8 was descriptive). The subjects were instructed to respond quickly, on the basis of a rapid first impression.

An unannounced recall test followed the rating phase after an interval of about $10 \mathrm{~min}$. The subjects had $10 \mathrm{~min}$ in which to write down as many of the 120 words as possible, in any order.

The retention interval was filled by the administration of two questionnaires. The first questionnaire was the Self-Consciousness Questionnaire (Buss, 1980), and the other was the State Anxiety Inventory (Spielberger, Gorsuch, \& Lushene, 1970).

\section{RESULTS}

Trait distinctiveness was defined by tabulating the number of words of each of the four subtypes: selfdescriptive and also other-descriptive (Both), selfdescriptive but not other-descriptive (Self-Only), not self-descriptive but descriptive of the other (OtherOnly), and not descriptive of either self or other (Neither). For purposes of analysis, responses 1-4 were considered nondescriptive and 5-8 were designated descriptive. The data were analyzed in a $2 \times 2 \times 2 \times 3$ design, with age (young, old) as a between-subjects factor and self (descriptive, nondescriptive), other (descriptive, nondescriptive), and likability as three within-subject factors (see Table 2). 
Table 2

Number Rated by Mutuality of Self- and Other-Descriptiveness, Latency (in Milliseconds) of Self-Reference Decision, and Probability of Recall

\begin{tabular}{|c|c|c|c|c|c|c|c|c|}
\hline & \multicolumn{4}{|c|}{ Elderly } & \multicolumn{4}{|c|}{ Young } \\
\hline & Both & Self Only & Other Only & Neither & Both & Self Only & Other Only & Neither \\
\hline \multicolumn{9}{|c|}{ Number } \\
\hline Like & 31.4 & 1.9 & 4.5 & 2.2 & 30.8 & 5.8 & 2.3 & 1.2 \\
\hline Neutral & 11.9 & 7.3 & 6.9 & 13.9 & 11.3 & 9.1 & 6.9 & 12.7 \\
\hline Unlike & 2.1 & 4.7 & 3.5 & 29.7 & 2.9 & 5.2 & 5.0 & 26.8 \\
\hline All & 45.4 & 13.9 & 14.9 & 45.8 & 45.0 & 20.1 & 14.2 & 40.7 \\
\hline \multicolumn{9}{|c|}{ Latency } \\
\hline Like & 4406 & 5091 & 4392 & 3900 & 3071 & 3274 & 3175 & 3558 \\
\hline Neutral & 5037 & 5382 & 5089 & 5076 & 3332 & 3449 & 3461 & 3564 \\
\hline Unlike & 4504 & 5084 & 4954 & 4302 & 3436 & 3468 & 3038 & 3238 \\
\hline All & 4654 & 5193 & 4806 & 4464 & 3275 & 3397 & 3233 & 3437 \\
\hline \multicolumn{9}{|c|}{ Probability of Recall } \\
\hline Like & .34 & .20 & .30 & .23 & .26 & .32 & .27 & .54 \\
\hline Neutral & .13 & .08 & .12 & .10 & .14 & .08 & .24 & .10 \\
\hline Unlike & .43 & .27 & .10 & .20 & .17 & .17 & .19 & .24 \\
\hline All & .29 & .18 & .17 & .17 & .19 & .19 & .23 & .26 \\
\hline
\end{tabular}

Note - "Both" refers to a word rated as descriptive of self and other; "self" refers to a word rated as descriptive of self but not descriptive of other; "other" refers to a word that was not self-descriptive but was other-descriptive; and "neither" refers to a word descriptive of neither self nor other.

\section{Endorsement of Items}

The number of items for each type revealed four significant interactions, but none involving age. The self $x$ other, self $x$ likability, other $x$ likability, and self $\mathrm{x}$ other $\mathrm{x}$ likability interactions were all significant $(\mathrm{Fs}>$ 18.69). There are clear gradients due to likability for the items judged to be mutually descriptive (Both) and mutually nondescriptive (Neither) for both young and elderly adults, but no such gradient for items that are uniquely descriptive (Self-Only).

Considering the most relevant items, the uniquely descriptive (Self-Only) items, some age differences are apparent. Specifically, the elderly subjects seemed relatively less generous toward themselves in terms of the number of likable items rated as Self-Only relative to Other-Only. That is, young adults accepted more likable items as being descriptive only of themselves (5.8) than were accepted as being descriptive only of their best friend (2.3), whereas the elderly were kinder to their best friend (1.9 vs. 4.5). This "altruism" was continued for the unlikable items in that the elderly attributed fewer of those to Other-Only than to SelfOnly ( 3.5 vs. 4.7 ), compared with young adults (5.2 vs. 5.0), thus behaving less defensively, perhaps.

\section{Latency of Self-Reference}

The speed of making a self-descriptiveness decision was significantly slower for elderly subjects (means = $4,778$ and $3,334 \mathrm{msec})[\mathrm{F}(1,18)=8.23]$. The interaction of age $\mathrm{x}$ self-descriptiveness was marginally significant $[F(1,18)=3.10, p<.10]$. Elderly subjects tended to be slower when an adjective was descriptive (pooling over Both and Self-Only) than when it was nondescriptive (pooling Other-Only and Neither) (means =
4,919 and $4,638 \mathrm{msec}$ ), whereas young adults showed no such difference (means $=3,337$ and 3,331 msec).

The only other significant effect was a main effect of likability $[F(2,36)=3.70]$, because the neutral items required more time (mean $=4,299 \mathrm{msec}$ ) than did the unlikable items (mean $=3,990 \mathrm{msec}$ ) and the likable items (mean $=3,866 \mathrm{msec}$ ). The age $\mathrm{x}$ likability interaction was not significant $(\mathrm{F}=1.30)$.

The comparison of greatest interest concerns the unique items (Self-Only) and mutually descriptive items (Both). Self-Only traits took more time for the elderly subjects at all levels of likability, and this was similarly true among the young adults, as was found by Mueller et al. (1984). In fact, this pattern seemed more pronounced for the elderly, in that they took $11.6 \%$ longer for decisions about the Self-Only items than for decisions about the Both items (pooling over likability), whereas the young adults took only $3.7 \%$ longer.

\section{Recall}

The probability of recall was computed by dividing the number recalled of each type (per likability level) by the number of items rated that way in the rating phase. There was no significant main effect for age $(\mathrm{F}<1)$, but the age $\mathrm{x}$ self-descriptiveness interaction was significant $[F(1,18)=6.84]$. Elderly subjects recalled more adjectives judged to be self-descriptive (Self-Only or Both) than those rated as being nondescriptive (Other-Only or Neither) (means $=.24$ and .17), whereas young adults actually showed the opposite pattern, recalling more nondescriptive items (means = .19 and .24). This effect collapses over uniqueness, however, and there was clearly no age difference in 
overall recall of the uniquely descriptive traits. However, compared with young adults, the elderly subjects did recall fewer likable and more unlikable Self-Only items and recalled more mutually descriptive items, especially unlikable shared features.

The only other significant main effect was for likability $[\mathrm{F}(2,36)=8.88]$, since likable items showed the highest level of recall (mean $=.28)$, followed by unlikable $($ mean $=.21)$ and neutral $($ mean $=.12)$ items. The age $x$ likability interaction was not significant $(F<1)$.

\section{DISCUSSION}

In this experiment, subjects defined traits as being uniquely descriptive by endorsing a trait adjective as being characteristic of themselves while rejecting it as nondescriptive of their best friend. It was clear that elderly subjects accepted fewer traits as being descriptive of Self-Only in general, and especially saw likable traits as being less characteristic of themselves alone, relative to young adults. This would indicate, on the surface, a less positive self-image for the elderly subjects. It is important to note that this is not the same as "more negative," in that the elderly subjects did not especially endorse more unlikable traits as being uniquely self-descriptive than did the college students. Since the elderly subjects also classified more traits as being descriptive of Neither, it might be that their acceptance of fewer likable items as being Self-Only reflects a response bias. However, that seems unlikely, because the age groups did not differ in terms of Other-Only and Both items. It seems most likely that the elderly do differ on this aspect of the self-image and see themselves in a "less positive" way than do younger people. This may reflect a more realistic view, in the same sense that depressed subjects may rate themselves more negatively than do nondepressed subjects, but the depressed subjects' ratings are more in accord with the ratings assigned to them by another person (Lewisohn, Mischel, Chaplain, \& Barton, 1980).

In terms of speed of access to personal information, the elderly were, in general, slower than the young adults, but the absence of interactions with age suggests that access to personal information is not qualitatively different for the elderly. As far as trait distinctiveness goes, elderly subjects clearly seemed to function more in accord with a comparative (i.e., situationally computed) process rather than with prestored information. That is, decisions about Self-Only items took more time than those about Both items, whereas the reverse would be expected if unique traits were the dominant features in a hierarchy of trait distinctiveness. This pattern of results suggests that trait distinctiveness does not become increasingly fixed and prestored with age, but, rather, continues to be situationally determined.

In sum, these results suggest that the self-reference phenomena observed by others using exclusively young adults are also found for elderly subjects. Apparently, when healthy elderly adults are required to perform self-comparisons, they obtain the same general memorial benefits as young adults, and can use the self-schema satisfactorily. Of course, these data cannot address directly the question of the relative value of selfcomparisons versus comparisons with other people because all subjects here had to reference both self and other targets; also, the data do not have much bearing on the issue of spontaneity, because all subjects were required to make self-reference judgments. The only data here that relate to the spontaneity issue are the lower scores by the elderly on the Buss (1980) SelfConsciousness Questionnaire (see Table 1). Assuming there is no instrument bias or response bias, this difference is in accord with the notion that elderly subjects are less spontaneously self-aware.

\section{REFERENCES}

ANDE RSON, N. H. (1968). Likableness ratings of 555 personalitytrait words. Journal of Personality and Social Psychology, 9, 272-279.

Buss, A. H. (1980). Self consciousness and social anxiety. San Francisco: Freeman.

Davis, H., \& Unruh, W. R. (1981). The development of the selfschema in adult depression. Journal of Abnormal Psychology, 90, 125-133.

Derry, P. A., \& Kuiper, N. A. (1981). Schematic processing and self-reference in clinical depression. Journal of Abnormal Psychology, 90, 286-297.

KAUSLER, D. H. (1982). Experimental psychology and human aging. New York: Wiley.

Keenan, J. M., \& BAILlet, S. D. (1980). Memory for personally and socially significant events. In R. S. Nickerson (Ed.), Attention and performance VIII (pp. 651-669). Hillsdale, NJ: Erlbaum.

Lewisohn, P. M., Mischel, W., Chaplain, W., \& Barton, R. (1980). Social competence and depression: The role of illusory self-perceptions. Journal of Abnormal Psychology. 89, 203-212.

McCrae, R. R., \& Costa, P. T. (1982). Self concept and the stability of personality: Cross-sectional comparisons of self reports and ratings. Journal of Personality and Social Psychology, 43, 1282-1292.

Muelle R, J. H. (1982). Self awareness and access to material rated as self-descriptive or nondescriptive. Bulletin of the Psychonomic Society, 19, 323-326.

Mueller, J. H., Ross, M. J., \& Heesacker, M. (1984). Distinguishing me from thee. Bulletin of the Psychonomic Society, 22, 79-82.

Rogers, T. B., Kuiper, N. A., \& Kirker, W. S. (1977). Selfreference and the encoding of personal information. Journal of Personality and Social Psychology, 35, 677-688.

RYFF, C. D. (1982). Self-perceived personality change in adulthood and aging. Journal of Personality and Social Psychology, 42, 108-115.

Salthouse, T. A. (1982). Adult cognition: An experimental psychology of human aging. New York: Springer-Verlag.

Spielberger, C. D., Gorsuch, R. L., \& Lushene, R. E. (1970). Manual for the State-Trait Anxiety Inventory. Palo Alto, CA: Consulting Psychologists Press.

TURner, R. G. (1980). Self-consciousness and memory of trait terms. Personality and Social Psychology Bulletin, 6, 273-277.

(Revision received for publication February 3, 1984.) 